\title{
Derleme
}

Mersin Univ Saglık Bilim Derg 2019;12(3):534-541

doi:10.26559/nersinsbd.590963

\section{Beyin ölümünde donör bakımı}

\author{
Aslınur Sagün, Nurcan Doruk \\ Mersin Üniversitesi Tıp Fakültesi, Anesteziyoloji ve Reanimasyon Anabilim Dalı, Mersin, Türkiye
}

\section{Öz}

Donör bakımı, son yıllarda "organ yönetimi" olarak adlandırılan yoğun bakımda beyin ölümü tanısı konulmuş hastalara uygulanan tedaviden oluşur. Beyin ölümünde donör adayının kardiak arrestine yol açabilecek hemodinamik, hormonal ve inflamatuvar bozukluklar görülebilir. $\mathrm{Bu}$ bozukluklar tedavi edilmezse transplante edilebilecek organ sayısı ve kalitesi düşebilir. Ayrıca donör bakımında hangi organın transplante edilmesi planlanıyorsa ona yönelik tedavi ve bakım uygulanmalıdır. Her biri ayrı öneme sahip bu bozukluklar son literatür taranarak incelenmiştir.

Anahtar kelimeler: Beyin ölümü, donörler, yoğun bakım

\section{Donor management of brain death}

\begin{abstract}
Donor management, recently described as "organ management", is composed by the treatment of the patients diagnosed with brain death in the intensive care unit. In the brain death, hemodynamic, hormonal and inflammatory disorders resulted in cardiac arrest of the donor candidate can be seen. Unless these disorders be treated, the number and the quality of the organs transplanted may decreased. Also, which organ is planned to be transplanted, treatment and care should be directed to this organ. These disorders having different importances were investigated by the recent literature.
\end{abstract}

Key words: Brain death, donors, critical care

\section{Yazının geliş tarihi: 11.09.2019 Yazının kabul tarihi: 07.11.2019}

Sorumlu yazar: Doktor Öğretim Üyesi Aslınur Sagün, Mersin Üniversitesi Tıp Fakültesi, Anesteziyoloji ve Reanimasyon Anabilim Dall, Tel: 05057167836, Eposta:aslınur_aslan@hotmail.com 


\section{Giriș}

Donör bakımı, beyin ölümü tanısı konulduktan organların alınmasına kadar geçen sürede, donöre yoğun bakımda uygulanan tedaviden oluşur. ${ }^{1} \mathrm{Bu}$ uygulamalara son yıllarda "organ yönetimi" ismi de verilmektedir. Yoğun bakım uygulamalarındaki yeniliklere ve beyin ölümü ile ilgili çalışmalara rağmen her geçen yll transplantasyon bekleyen hasta ile organ donörü sayısı arasındaki fark artmaktadır. ${ }^{2}$ $\mathrm{Bu}$ dönemde aktif bir tedavi uygulanırsa transplante edilebilecek organ sayısı artacaktır. Transplantasyon için organ sayısı kadar organ fonksiyonu ve alıcının yaşam kalitesi de önemlidir.

Beyin ölümünde potansiyel donör adayının kardiak arrestine veya farklı organlarda irreversibl hasara yol açabilecek hemodinamik, hormonal ve inflamatuvar bozukluklar görülebilir. ${ }^{3}$ Ayrı ayrı sistemlerdeki etkilerine bakacak olursak, pulmoner ödem, hipotansiyon, aritmi, diabetes insipidus, hormonal ve metabolik bozukluklar, koagülopati, akut böbrek hasarı, inflamatuvar olaylar ve hipotermi en belirgin olanlardır.

\section{Monitörizasyon}

Potansiyel organ donörlerine de diğer yoğun bakım hastalarına olduğu gibi elektrokardiyogram, soluk sonu karbondioksit, arteryel kanülasyon, santral venöz basınç kateterizasyonu, vücut ısısı ölçümü, idrar sondası ile rutin monitörizasyon uygulanmalıdır. ${ }^{4}$ İnvaziv monitörizasyonda hem sayısal değerler hem de traseler özellikle hemodinamiyi değerlendirmede önemlidir. Kalp atım hızının 60-120 atım/dk, ortalama arter basincinın $\geq 70 \mathrm{mmHg}$, santral venöz basıncın 6-10 mmHg, idrar çıkışının 0,5-3 $\mathrm{ml} / \mathrm{kg} / \mathrm{st}$ olması istenir. ${ }^{5}$ Bunun yanında elektrolit değerlerinin de normal sınırlarda olması gerekir.

Rutin monitörizasyonla hemodinamik bozukluklar kontrol altına alınamıorsa, akciğer veya kalp transplantasyonu planlaniyorsa, inotrop veya kronotrop ihtiyacı fazla ise pulmoner arter kateterizasyonu ve kardiyak output ölçümü öneriler arasındadır.

\section{Kardiyovasküler destek}

\section{Katekolamin firtınası}

Her ne kadar beyin ölümü patofizyolojisi çok net olarak bilinmiyorsa da intrakranial basınç artışının, beyin ölümü tanısını koyduran en önemli faktör olduğu bilinmektedir. Artmış intrakranial basınç ve serebellar herniasyon, pontin iskemiye yol açar. Pontin iskemi sonucunda hem vagal hem de sempatik yanıt oluşur, klinik olarak bradikardi ve hipertansiyon görülür. Pontin iskemi serebellar medullaya doğru ilerledikçe vagal nükleusta, sempatik uyarıyı dengeleyemeyecek şekilde iskemi gelişir. Endojen katekolaminler hizla artar ve klinik olarak taşikardi, hipertansiyon, kardiyak output artışı, yani, miyokardın oksijen tüketiminde artış ortaya çıkar. Bunların sonucunda yapısal kalp hasarı ve pulmoner vasküler direnç artışına bağlı pulmoner ödem gelişir. ${ }^{6}$ Sadece akciğerler değil diğer organlar da sistemik vasküler direnç artışından etkilenir. $\mathrm{Bu}$ endojen katekolaminlerin hızla arttığı döneme "katekolamin firtınası" denir. Donörlerin \% 63'ünde ortaya çlktığı ve $30 \mathrm{dk}$ ile 6 saat arasında (ortalama 1 saat) sürdüğü bilinmektedir. ${ }^{7} \mathrm{Bu}$ dönemin etkili ve zamanında tedavi edilmesiyle, transplante edilebilecek organ sayısı ve kalitesinin arttığını gösteren çalışmalar mevcuttur. Genellikle tek başına kısa etkili beta bloker ile hemodinamik bozukluk düzeltilebilirse de bazen beta blokere ek olarak nitroprussid, urapidil, nikardipin gibi bir vazodilatöre de ihtiyaç duyulabilir. Tedavi hastanın yanıtına göre düzenlenebilir.

\section{Vazoaktif ilaç kullanımı}

Beyin sapındaki iskemi ilerledikçe, spinal kordda deaktivasyon belirginleşir. Deaktivasyona bağlı olarak katekolamin ve vazomotor tonüs kaybı meydana gelir. Klinik olarak atropine yanitsız bradikardi ve hipotansiyon ortaya çıkar. Vazomotor tonüs kaybı, inflamatuvar mediatörlerin salınımına bağlı da gelişir. Bu durumda vasküler tonüsü düzeltmek için vazoaktif ilaçlar kullanmak gerekir. ${ }^{8} \mathrm{Bu}$ ilaçları kullanırken dikkat edilmesi gereken en önemli konu doz ayarlamasıdır. Uzun süre yüksek doz kullanmak yapısal kalp hasarına yol açabilir. Vazoaktif ilaç kullanımında hedef ortalama 
arter basıncının 65-90 $\mathrm{mmHg}$ aralığında tutulmasıdır. Son yıllarda yapılan pek çok çalışmada vasküler tonüsü düzeltmede vazopressinin daha etkin olduğu, katekolamin gerekiyorsa mümkünse en düşük doz noradrenalin ile başlamak gerektiği özellikle vurgulanmaktadır.9-11 Harbor-Ucla Medical Center grubunun 10.000 hastanın verileriyle yaptığ çalışmalarda vazopressinin beyin ölümü gerçekleşen bireylerde rutin olarak kullanılması önerilmiştir. ${ }^{12}$ Araştırmacılar vazopressin uygulanilan grupta transplante edilebilecek organ sayısında artış olduğunu belirtmişlerdir. $\mathrm{Bu}$ çalışmalardaki çelişki, vazopressinin diabetes insipidus için $\mathrm{mi}$ yoksa hemodinamik stabilite için mi kullanıldığı belirtilmemiştir. Vazopressin bulunmadığı durumlarda, V1 reseptörüne spesifik sentetik analoğu olan terlipressin kullanılabilir. Terlipressinin ciddi hipotansiyonun düzeltilmesinde faydalı olduğu ve noradrenalin ihtiyacını önemli ölçüde azalttığı gösterilmiştir. ${ }^{13}$ Yine de uzun dönem greft fonksiyonuna etkileriyle ilgili net bir bilgi bulunmamaktadır.

Bunun yanında, 2005 yılında Cuende ve ark.'nın yayınladığı bir çalışmada noradrenalin kullanımının greft survivalini artırdığı gösterilmiştir. ${ }^{14}$

Sonuç olarak son öneriler ışı̆̆ı̆nda, vazoaktif ilaç kullanımında ilk tercih edilecek ajan vazopressin, ihtiyaç duyulması halinde düşük doz noradrenalin veya dopaminin ek olarak kullanılmasıdır. Düşük dozdan kasıt, dopamin için $10 \mathrm{mcg} / \mathrm{kg} / \mathrm{dk}$, noradrenalin için ise $0,5 \mathrm{mcg} / \mathrm{kg} / \mathrm{dk}^{\prime}$ ıın altıdır.

\section{Sivı yönetimi}

Sıvı yönetimi bu hastalarda tartışmalı olsa da hedef olarak santral venöz basincin 3-8 mmHg, ortalama arter basıncının 65-90 mmHg olacak şekilde ihtiyaca göre kristalloid veya kolloid infüzyonu önerilmektedir. ${ }^{15}$ Sıvı yönetiminde asıl belirleyici olan ise hangi organın transplante edilmesinin planlandığıdır. Kalp veya akciğer transplantasyonu planlanan donörlerde restriktif sıvı tedavisi uygulanırken, böbrek transplantasyonu planlanan donörlerde liberal yaklaşım tercih edilmelidir.
Diabetes insipidus gelişimi de sıvı tedavisi için önemli bir faktördür. Hastanın yanıtına göre sıvı infüzyonu ayarlanmalıdır. Anemi veya kan kaybı varsa, $\mathrm{Hb}<6 \mathrm{gr} / \mathrm{dL}$ ise eritrosit süspansiyonu transfüzyonu uygulanmalıdır. ${ }^{16}$ Taze donmuş plazma, trombosit süspansiyonu veya aferez trombosit gibi kan ürünleri uygulamak için ise klinik bulgular, koagülasyon testleri değerlendirilmelidir. ${ }^{17}$

Beyin ölümünde elektrolit bozuklukları ile de sıklıkla karşılaşılır. Özellikle hipernatremi mevcutsa, hastalara sodyum içermeyen sıvılar uygulanmalıdır. $\mathrm{Bu}$ amaçla \%5 Dekstroz uygulanabilir, hiperglisemi varsa insülin eklenmelidir.

\section{Pulmoner destek}

Beyin ölümünde hemodinamik, inflamatuvar ve endokrin nedenlerle akciğer hasarı gelişebilir. Özellikle akciğer transplantasyonu planlanan donörlerde pulmoner desteğin 3 amacı vardır, bunlar; potansiyel greftin oksijenasyonunu iyileștirmek, beyin ölümüne bağlı komplikasyonları minimalize etmek ve yoğun bakımda uzun süre yatışa neden olabilecek pnömoni, sıvı yüklemesi ve barotravma gibi olayları önlemektir.18 $\mathrm{Bu}$ amaçla düşük tidal volüm (6-8 mL/kg), PEEP (5-10 $\left.\mathrm{cmH}_{2} \mathrm{O}\right)$ ve rekrüitment manevrasını içeren akciğer koruyucu ventilasyon uygulanır. Yüksek $\mathrm{FiO}_{2}$ 'ye rağmen düşük $\mathrm{PO}_{2}$ mevcutsa bronkoskopi uygulanabilir. Bronkoskopi ile mukus tıkacı veya kan pıhtıları temizlenebilir, havalanmayan akciğer alanları bu şekilde açılabilir. Bununla birlikte restriktif sıvı tedavisi, inhalasyon havasını ısıtmak, nemlendirmek gerekir. İnhaler terbutalinin, beta adrenerjik stimülasyon aracıllğıyla alveolar sıvı klirensini artırdığı gösterilmiştir. ${ }^{19} \quad 0$ nedenle pulmoner destek tedavisinin bir parçası olarak uygulanabilir. Ayrıca, ventilatör ilişkili pnömoniyi önlemek için özellikle akciğer grafisinde infiltrasyonların izlendiği hastalara antibiyotiklerin rutin uygulanması da öneriler arasındadır. ${ }^{20}$ Antibiyotik tedavisinden maksimum fayda sağlamak için diğer yoğun bakım hastalarında olduğu gibi trakeal sekresyon örneği alınması ve kültür incelemesi yapmak faydalıdır. 
Hormonal destek

Donör bakımının en önemli ve tartışılan komponentlerinden birisi de hormonal tedavidir. Beyin ölümünde hipotalamus ve hipofizin kan akımının bozulması sonucunda hormonal üretim azalır. Klinik etkilerine bakacak olursak, antidiüretik hormon eksikliğine bağlı olarak diabetes insipidus, diürez, hipovolemi, relatif hipernatremi, tiroid hormonlarının eksikliğinde kardiyak kontraktilitede azalma, anaerobik metabolizmada artış, kortizol eksikliğinde inflamatuvar yanitta artış, hemodinamik instabilite ve insülin eksikliğinde hiperglisemi, renal ve pankreatik greft malfonksiyonu gözlenir.

United Network for Organ Sharing'in önerilerine göre hormon replasman tedavisinde tüm hormonlar kombine olarak uygulanması daha etkili bulunmuştur. ${ }^{21}$

Antidiüretik hormon eksikliğine bağlı gelişen diabetes insipidus en sık (\% 4687) görülen hormonal bozukluktur. Donörün idrar çıkışının 2 saatten uzun süre boyunca $250 \mathrm{~mL} /$ saat'in üzerinde olması tanı için belirleyicidir. Tedavisinde vazopressin veya sentetik derivesi olan desmopressin kullanılabilir. ${ }^{22}$ Desmopressin sadece renal etkiye sahip olduğu için hipovolemi hemodinamik bozukluğa yol açmadıysa tercih edilmesi gereken ajan olarak önerilir. Önerilen desmopressin dozu bolus olarak 1$4 \mu \mathrm{g}$ (intravenöz) veya devamlı infüzyon olarak 0.5-2 $\mu \mathrm{g}$ (intravenöz). ${ }^{23}$

Hormon replasman tedavisinin komponentlerinden olan tiroid hormonu ile ilgili çelişkili öneriler olmasına rağmen birçok sisteme pozitif etkilerinden dolayı uygulanması önerilmektedir. Tiroid replasmanı ile miyokardial kontraktilite ve transplante edilebilecek organ sayısında artış, inotrop ihtiyacı ve akut rejeksiyon insidansında azalma bildirilmiștir. ${ }^{24}$ Bazı çalışmalarda tiroid hormonu replasmanında T4 bazılarında ise T3 hormonu kullanılmıştır. T4 dozu sıklıkla $20 \mathrm{mg}$ bolus (intravenöz), takibinde $10 \mathrm{mg} / \mathrm{saat}$ sabit hızda (intravenöz infüzyon) olarak uygulanmıştır. ${ }^{25-27}$ T3'ün ise farklı dozlarda kullanımı mevcuttur, sabit $2 \mathrm{mg}$ veya vücut ağırlığına göre $0.2-0.4 \mathrm{mg} / \mathrm{kg}$ tekrarlayan bolus dozları uygulanabilir. ${ }^{28}$
Kortikosteroid uygulaması da yaygın olarak yapılmaktadır. Beyin ölümü gerçekleşen olguların yaklaşık \%75'inde adrenal yetmezlik ortaya çıkar. Tanı koymak için serum kortizol düzeyi bakılabilir veya ACTH testi uygulanabilir. ACTH stimülasyon testine zaylf yanit varsa ve serum kortizol düzeyi düşük ise tanı kesinleştirilir. Adrenal yetmezlik gözlenen donörlerde hemodinamik instabilite gelişir. Yakın zamanda yapılan çok merkezli prospektif randomize CORTICOME çalışmasında bir grup hastaya hidrokortizon verilmiş bir gruba ise verilmemiştir. Hidrokortizon verilen grupta norepinefrin dozunun daha düşük olduğu ve hemodinamik stabilitenin daha çabuk sağlandığı saptanmıştır ${ }^{29}$. Kortikosteroid dozu ile ilgili kesin bir değer olmamakla birlikte genellikle metilprednizolon ilk tercih edilen ajandır ve $15-60 \mathrm{mg} / \mathrm{kg}$ uygulanması önerilir. ${ }^{27}$

\section{Elektrolit bozuklukları}

Poliüri ve homeostatik değişiklikler potasyum, magnezyum ve kalsiyumda hizlı değişikliklere yol açabilir. Hem diabetes insipidus hem de \%0,9 $\mathrm{NaCl}^{\prime}$ nin devaml uygulanması nedeniyle hipernatremi sık görülür. Hipernatremi olan hastalarda özellikle karaciğer greft başarısı düşük olarak bulunmuştur. ${ }^{30}$ Altta yatan diabetes insipidus tedavisi ve hipotonik çözeltilerin infüzyonu ile tedavi edilebilir.

\section{Glukoz kontrolü}

Kontrolsüz hiperglisemi özellikle renal ve pankreatik greft malfonksiyonu için risk faktörüdür. Kan glukozunun 120-180 $\mathrm{mg} / \mathrm{dL}$ olacak şekilde insülin tedavisi önerilir. ${ }^{31}$

\section{Vücut IsISI}

Beyin ölümünde hipotalamusun kan akımının bozulmasına bağlı olarak hipotermi ve poikilotermi (ortam ısısına göre vücut sıcaklığını regüle edilememesi) sık gözlenir.17 Hipotermiye bağlı enzimatik disfonksiyon, sonuçta inflamasyon artışı ve vazomotor kontrol kaybı ortaya çıkar. Organ donörlerinde normotermik ortak öneridir. 
Tablo 1. Beyin ölümünde donör bakımı ile ilgili öneriler

\begin{tabular}{|c|c|}
\hline & Öneri \\
\hline Monitörizasyon & $\begin{array}{l}\text { Elektrokardiyogram, periferik oksijen satürasyonu, arteryel } \\
\text { kanülasyon, santral venöz basınç monitörizasyonu, vücut ısısı ölçümü, } \\
\text { idrar sondası }\end{array}$ \\
\hline Önerilen değerler & $\begin{array}{l}\text { Kalp atım hızı } 60-120 \text { atım/dk, } \\
\text { Ortalama arter basıncı } \geq 70 \mathrm{mmHg} \text {, } \\
\text { Santral venöz basınç 6-10 mmHg, } \\
\text { İdrar çıkışı } 0,5-3 \mathrm{ml} / \mathrm{kg} / \mathrm{st}\end{array}$ \\
\hline \multicolumn{2}{|l|}{ Kardiyovasküler } \\
\hline Katekolamin firtınası & $\begin{array}{l}\text { Kisa etkili beta bloker } \\
\text { Nitroprussid } \\
\text { Urapidil } \\
\text { Nikardipin }\end{array}$ \\
\hline Vazoaktif ilaç kullanımı & $\begin{array}{l}\text { Vazopressin } \\
\text { Terlipressin } \\
\text { Noradrenalin } \\
\text { Dopamin }\end{array}$ \\
\hline Sıvı yönetimi & $\begin{array}{l}\text { Santral venöz basınç } 3-8 \mathrm{mmHg} \text {, Ort. arter basıncı } 65-90 \mathrm{mmHg} \text { olacak } \\
\text { șekilde kristalloid, kolloid } \\
\mathrm{Hb}<6 \mathrm{~g} / \mathrm{dl} \text { ise eritrosit süspansiyonu }\end{array}$ \\
\hline Pulmoner destek & $\begin{array}{l}\text { Düşük tidal volüm }(6-8 \mathrm{~mL} / \mathrm{kg}) \\
\text { PEEP }\left(5-10 \mathrm{cmH}_{2} \mathrm{O}\right) \\
\text { Rekrüitment manevrası } \\
\text { Profilaktik antibiyotik }\end{array}$ \\
\hline Hormonal destek & $\begin{array}{l}\text { T 4: } 20 \mathrm{mg} \text { bolus (intravenöz), takibinde } 10 \mathrm{mg} / \mathrm{saat} \text { sabit hızda } \\
\text { (intravenöz infüzyon) } \\
\text { T 3: } 0.2-0.4 \mathrm{mg} / \mathrm{kg} \text { veya } 2 \mathrm{mg} \text { (total) } \\
\text { Metilprednizolon ilk tercih edilen ajandır ve } 15-60 \mathrm{mg} / \mathrm{kg}\end{array}$ \\
\hline Glukoz kontrolü & Kan glukoz değeri 120-180 mg/dL olacak şekilde insülin \\
\hline Vücut ısısı & Normotermi $\left(35,5-36,5^{0} \mathrm{C}\right)$ \\
\hline
\end{tabular}

Fakat 2015 yılında Niemann ve ark.'nın yaptığı bir çalışmada toplam 370 hastadan bir grubuna normotermi $(36,5-$ $\left.37,5^{\circ} \mathrm{C}\right)$ bir grubuna ise hipotermi $\left(34-35^{\circ} \mathrm{C}\right)$ uygulanmıș, hipotermi grubunda renal transplantasyon başarısı daha yüksek bulunmuştur.32 Bu çalışmadan elde edilen sonuçların başka çalışmalarla desteklenmesi gerektiği düşünülmüştür.

\section{Enteral beslenme}

Enteral beslenmenin devamı ile ilgili çelişkili öneriler vardır. Karaciğer glikojen rezervini ve intestinal tropizmi sağlamak için enteral beslenme önerilmekle birlikte vagal tonüs kaybına bağlı besin emiliminde

bozulma nedeniyle bir fayda sağlamadığı ile ilgili öneriler mevcuttur.33

\section{Diğer öneriler}

Yukarıda bahsedilenlerin dışında
beyin ölümü gerçekleşen hastalarda
antikonvülzan, ozmotik diüretikler gibi
gereksiz ilaçların kesilmesi önerilir.
Antibiyotikler, derin ven trombozu
profilaksisi gibi medikasyonların ise devam
edilmesi önerilir.2 Ayrıca, özellikle beyin


dokusundan salgılanan doku tromboplastine bağlı koagülasyon bozuklukları gözlenebilir, bu durumda Htc > \%30, Hb > $10 \mathrm{~g} / \mathrm{dL}$ olmalıdır.34 yönetimi

Organ alınması sırasında anestezi

Donör bakımı organların ameliyathanede alınmasından sonra sona erer. 0 yüzden organ donörünün ameliyathanede organların çıkarılması sırasında da yakın takibe ihtiyacı vardır. Ameliyathanede organ çıkarılması sırasında havayolu ile ilgili herhangi bir sorun olmadığından emin olunmalıdır. Vazoaktif ilaçlar başlandıysa devam edilmeli, başlanmadiysa hazır bulundurulmalıdır. Spinal refleksler intakt olabilir ve cerrahi uyarıyla kas hareketi gözlenebilir, o yüzden ihtiyaç duyulması halinde kas gevşetici uygulanabilir. Hipertansiyon varsa vazodilatör, opioid ve anestezik ajanlar ile kontrol altına alınmall, hemodinamik monitörizasyon ile elde edilen verilere göre sıvı tedavisi uygulanmalıdır. ${ }^{35}$

\section{Sonuç}

Bu konuyla ilgili çalışmaların birçoğu retrospektiftir ve tam bir fikir birliği yoktur. Bazı tedavi yöntemleri beyin ölümüne spesifik değildir, diğer yoğun bakım hastaları ile aynıdır. Beyin ölümü patofizyolojisine göre tedavi uygulamak transplante edilecek organların niceliği ve niteliği bakımından önemlidir. Zaman yönetimi donör bakımında hem organları değerlendirmede hem de organların alınması için optimal koşulları sağlamada önemlidir. ${ }^{36}$ Beyin ölümü tanısı konduğu anda değerlendirilen bazı organlar transplantasyon için uygun kabul edilmezken birkaç saat sonra uygun olarak değerlendirilebilir. Bu durumlar her donör için ayrı ve özenli bir şekilde yönetilmelidir. Sonuç olarak beyin ölümünde donör bakımı kapsamlı olmalı, tek bir noktaya değil tüm bozukluklara odaklanmalı ve uygun bakım yöntemleri tercih edilmelidir. Ancak bu şekilde transplante edilebilecek organ sayısı artırılabilir ve organ bekleyen hastalara daha fazla şans sağlanabilir.

\section{Kaynaklar}

1. Xia VW, Braunfeld M. Anesthesia Management of Organ Donors. Anesthesiol Clin. 2017;35(3):395-406. doi: 10.1016/j.anclin.2017.04.003.

2. Chamorro-Jambrina C, Muñoz-Ramírez MR et al. Organ donor management: Eight common recommendations and actions that deserve reflection. Med Intensiva. 2017;41(9):559-568.

doi: 10.1016/j.medin.2017.01.012.

3. Domínguez-Roldán JM, García-Alfaro C, Jimenéz-González PI, Hernández-Hazañas F, Gascón Castillo ML, Egea Guerrero JJ. Muerte encefálica: repercusión sobre órganos y tejidos. Med Intensiva. 2009;33:434-441.

4. Souter MJ, Eidbo E, Findlay JY, Lebovitz DJ, Moguilevitch M, Neidlinger NA, Wagener G, Paramesh AS, Niemann CU, Roberts PR, Pretto EA Jr Organ Donor Management: Part 1. Toward a Consensus to Guide Anesthesia Services During Donation After Brain Death. Semin Cardiothorac Vasc Anesth. 2018;22(2):211-222. doi: $10.1177 / 1089253217749053$.

5. Shemie SD, Ross H. Pagliarello J, Baker AJ, Greig PD, Brand T, Cockfield S, Keshavjee S, Nickerson P, Rao V, Guest C, Young K, Doig C; Pediatric Recommendations Group. Organ donor management in Canada: recommendations of the forum on medical management to optimize donor organ potential. Can Med Assoc J 2006;174:S13-30.

6. Wood KE, Becker BN, McCartney JG, D'Alessandro AM, Coursin DB. Care of the potential donor. $N$ Engl $J$ Med. 2004;351:2730-2729.

7. Audibert G, Charpentier C. Seguin-Devaux C, Charretier PA, Grégoire H, Devaux Y, Perrier JF, Longrois D, Mertes PM. Improvement of donor myocardial function after treatment of autonomic storm during brain death. Transplantation. 2006;82:10311036.

8. Bugge JF. Brain death and its implications for management of the potential organ donor. Acta Anaesthesiol Scand. 2009;53:1239-1250.

9. Mascia L, Mastromauro I, Viberti S, Vincenzi M, Zanello M. Management to 
optimize organ procurement in brain dead donors. Minerva Anestesiol. 2009;75:125133.

10.Dictus C, Vienenkoetter B. Esmaeilzadeh M, Unterberg A, Ahmadi R. Critical care management of potential organ donors: our current standard. Clin Transpl. 2009;23:2-9.

11.Dikdan GS, Mora-Esteves C, Koneru B.Abstract Review of randomized clinical trials of donor management and organ preservation in deceased donors: opportunities and issues. Transplantation. 2012;94:425-441.

12. Plurad DS, Bricker S, Neville A, Bongard F, Putnam B. Arginine vasopressin significantly increases the rate of successful organ procurement in potential donors. Am J Surg. 2012;204:856-860.

13. Piazza O, Scarpati G, Rispoli F, Iannuzzi M, Tufano R, De Robertis E. Terlipressin in brain-death donors. Clin Transplant. 2012;26(6):E571-575.

14. Cuende N, Miranda B, Cãnón JF, Garrido G, Matesanz R. Donor characteristics associated with liver graft survival. Transplantation. 2005;79:1445-1452.

15. Malinoski DJ, Daly MC. Patel MS, OleyGraybill C, Foster CE 3rd, Salim A. Achieving donor management goals before deceased donor procurement is associated with more organs transplanted per donor. J Trauma. 2011;71(4):990-995; discussion 996. doi: 10.1097/TA.0b013e31822779e5.

16. American Society of Anesthesiologists Task Force on Perioperative Blood Management. Practice guidelines for perioperative blood management: an updated report by the American Society of Anesthesiologists Task Force on Perioperative Blood Management. Anesthesiology. 2015;122:241-275.

17. Souter M, Eidbo E et al. Organ Donor Management: Part 1. Toward a Consensus to Guide Anesthesia Services During Donation After Brain Death. Seminars in Cardiothoracic and Vascular Anesthesia 2018;22: 211-222

18. Venkateswaran RV, Patchell VB Wilson IC, Mascaro JG, Thompson RD, Quinn DW, Stockley RA, Coote JH, Bonser RS. Early donor management increases the retrieval rate of lungs for transplantation. Ann Thorac Surg. 2008 85(1):278-286.

19. Ware LB, Fang X Wang Y, Sakuma T, Hall TS, Matthay MA. Selected Contribution: Mechanisms that may stimulate the resolution of alveolar edema in the transplanted human lung. J Appl Physiol 93: 2002;1869-1874.

20. de Perrot M, Weder W, Patterson GA, Keshavjee S.. Strategies to increase limited donor resources. Eur Respir J. 2004;23(3):477-482.

21. Zaroff JG, Rosengard BR, Armstrong WF, Babcock WD, D'Alessandro A, Dec GW, Edwards NM, Higgins RS, Jeevanandum V, Kauffman M, Kirklin JK, Large SR, Marelli D, Peterson TS, Ring WS, Robbins RC, Russell SD, Taylor DO, Van Bakel A, Wallwork J, Young JB. Consensus conference report: Maximizing use of organs recovered from the cadaver donor: Cardiac recommendations, Circulation 2002; 106:836-841.

22. Kotloff RM, Blosser S. Fulda GJ, Malinoski D, Ahya VN, Angel L, Byrnes MC, DeVita MA, Grissom TE, Halpern SD, Nakagawa TA, Stock PG, Sudan DL, Wood KE, Anillo SJ, Bleck TP, Eidbo EE, Fowler RA, Glazier AK, Gries C, Hasz R, Herr D, Khan A, Landsberg D, Lebovitz DJ, Levine DJ, Mathur M, Naik P, Niemann CU, Nunley DR, O'Connor KJ, Pelletier SJ, Rahman O, Ranjan D, Salim A, Sawyer RG, Shafer T, Sonneti D, Spiro P, Valapour M, Vikraman-Sushama D, Whelan TP; Society of Critical Care Medicine/American College of Chest Physicians/Association of Organ Procurement Organizations Donor Management Task Force. Management of the potential organ donor in the ICU: Society of Critical Care Medicine/American College of Chest Physicians/Association of Organ Procurement Organizations Consensus Statement. Crit Care Med. 2015;43:12911325.

23. Hahnenkamp K, Böhler $\mathrm{K}$, Wolters $\mathrm{H}$, Wiebe K, Schneider D, Schmidt HH. OrganProtective Intensive Care in Organ Donors. Dtsch Arztebl Int. 2016:22;113(33-34):552558.

24. Macdonald PS, Aneman A, Bhonagiri D, Jones D, O'Callaghan G, Silvester W, Watson 
A, Dobb G. A systematic review and metaanalysis of clinical trials of thyroid hormone administration to brain dead potential organ donors. Crit Care Med 2012:40;5: 1635-1644.

25. Van Bakel AB, Pitzer S, Drake P, Kay NA, Stroud M, Sade RM. Early hormonal therapy stabilizes hemodynamics during donor procurement. Transplant Proc 2004; 36:2573-2578.

26. Salim A, Velmahos GC, Brown C, elzberg $\mathrm{H}$, Demetriades D.Aggressive organ donor management significantly increases the number of organs available for transplantation. J Trauma 2005;58:991-994.

27. Nath DS, Ilias Basha H, Liu MH, Moazami $\mathrm{N}$, Ewald GA. Increased recovery of thoracic organs after hormonal resuscitation therapy. J Heart Lung Transplant 2010;29:594-596.

28. Roels L, Pirenne J, Delooz H, Lauwers P, Vandermeersch E. Effect of triiodothyronine replacement therapy on maintenance characteristics and organ availability in hemodynamically unstable donors. Transplant Proc 2000; 32:1564-1566.

29. Pinsard M, Ragot S, Mertes PM, Bleichner JP, Zitouni S, Cook F, Pierrot M, Dube L, Menguy E, Lefèvre LM, Escaravage L, Dequin PF, Vignon P, Pichon N. Interest of low-dose hydrocortisone therapy during brain-dead organ donor resuscitation: the CORTICOME study. Crit Care. 2014;23;18(4):R158. doi: 10.1186/cc13997.

30. Fridell JA, Vianna RM, Milgrom ML, Chestovich P, Vandenboom C, Tector AJ. Severe hypernatremia in deceased liver donors does not impact early transplant outcome. Transplantation 2010;90:438443.

31. Sally MB, Ewing T, Crutchfield M, Patel MS, Raza S, De La Cruz S, Zatarain J, Malinoski DJ; United Network for Organ Sharing (UNOS) Region 5 Donor Management Goals (DMG) Workgroup. Determining optimal threshold for glucose control in organ donors after neurologic determination of death: a United Network for Organ Sharing Region 5 Donor Management Goals Workgroup prospective analysis. J Trauma Acute Care Surg. 2014;76:62-68.
32. Niemann CU, Feiner J, Swain S, Bunting $S$, Friedman M, Crutchfield M, Broglio K, Hirose R, Roberts JP, Malinoski D. Therapeutic hypothermia in deceased organ donors and kidney graft function. $N$ Engl $J$ Med. 2015;373:405-414.

33. Hergenroeder GW, Ward $\mathrm{NH}, \mathrm{Yu} \mathrm{X}$, Opekun A, Moore AN, Kozinetz CA, Powner DJ. Randomized trial to evaluate nutritional status and absorption of enteral feeding after brain death. Prog Transpl. 2013;23:374-382.

34. Zaroff JG, Rosengard BR, Armstrong WF, Babcock WD, D'Alessandro A, Dec GW, Edwards NM, Higgins RS, Jeevanandum V, Kauffman M, Kirklin JK, Large SR, Marelli D, Peterson TS, Ring WS, Robbins RC, Russell SD, Taylor DO, Van Bakel A, Wallwork J, Young JB. Consensus conference report: maximizing use of organs recovered from the cadaver donor: cardiac recommendations, Circulation. 2002;13;106(7):836-841.

35. Pennefather S. Hemodynamic responses to noxious stimuli in brain-dead organ donors. Intensive Care Med 1994;20:165166.

36. McKeown DW, Bonser RS, Kellum JA. Management of the heartbeating brain-dead organ donor. Br J Anaesth. 2012: 108 Suppl 1:i96-107. 